\title{
Criação de objeto digital como suporte para aprendizagem de Combinatória nos Anos Iniciais
}

\author{
Elisa Friedrich Martins - PGIE - UFRGS - titamat@yahoo.com.br \\ Lucas Vieira Lima - IME - UFRGS - lucaz.vl1@gmail.com \\ Marcus Vinicius de Azevedo Basso - IME - PPGEMat - PGIE - UFRGS - mbasso@ufrgs.br
}

\section{Resumo}

Nesse artigo, apresenta-se as etapas de desenvolvimento de um Objeto Digital de Aprendizagem (ODA) utilizado em pesquisa sobre o pensamento combinatório de estudantes dos Anos Iniciais. Os requisitos do ODA, assim como seus aspectos técnicos e teóricos, são apresentados de maneira a elucidar sua criação e desenvolvimento. Apresenta-se a cronologia da criação, desde a primeira versão até sua versão atual bem como os resultados do uso com alunos dos anos iniciais de uma escola pública do Ensino Fundamental. A importância desse tipo de material e a relevância de sua utilização nas escolas são aspectos discutidos no texto. A partir dos dados produzidos até o presente momento, pode-se dizer que sua utilização é adequada para a faixa etária para o qual foi planejado, constituindo-se em material que pode favorecer a aprendizagem das primeiras noções de Análise Combinatória por alunos dos Anos Inicias do Ensino Fundamental.

Palavras-chave: combinatória, matemática, anos iniciais, objeto de aprendizagem.

\section{Digital Object Creation as a Support for learn Combinatorics at the early years of Elementary School Learning}

\begin{abstract}
In this article we present the development stages of a Digital Learning Object used in research on the combinatorial thinking of early years students. The requirements of the Digital Learning Object, as well as its technical and theoretical aspects, are presented in order to elucidate its creation and development. We present the chronology of creation, from the first version to its current version as well as the results of the use with students of the initial years of a public elementary school. The importance of this type of material and the relevance of its use in schools are aspects discussed in the text. From the data produced up to the present time, it can be said that its use is adequate for the age group for which it was planned, constituting itself in material that can favor the learning of the first notions of Combinatorial Analysis by students of the beginning years of Elementary School.
\end{abstract}

Keywords: combinatorial, mathematics, elementary school, object of learning.

\section{Introdução}

O Objeto Digital de Aprendizagem ${ }^{1}$ (ODA) apresentado neste artigo foi desenvolvido para a produção de dados da pesquisa de doutoramento em Informática na Educação, na Universidade Federal do Rio Grande do Sul - Brasil. Buscas por materiais sobre a Análise Combinatória para os Anos Iniciais do Ensino Fundamental evidenciaram uma lacuna de materiais do tipo e levaram ao desenvolvimento de tal recurso (Basso e

${ }^{1} \mathrm{O}$ desenvolvimento do ODA foi financiado pela Secretaria de Educação a Distância (SEAD) da Universidade Federal do Rio Grande do Sul (UFRGS) por meio do Edital UFRGS EaD 25, dentro da Linha $\mathrm{C}$ - Recursos Educacionais Digitais. 
Martins, 2018). A partir da teoria de Construção de Conhecimento de Jean Piaget e com os princípios do Método Clínico Piagetiano, se elaborou um material que permite a ação sobre os problemas envolvendo Combinatória. O ODA denominado MDMat Combinatória, é parte dos materiais desenvolvidos no Projeto MDMat - Mídias Digitais para Matemática e encontra-se disponível em http://odin.mat.ufrgs.br/combinatoria/. O uso de um objeto digital permite que, ao mesmo tempo e na mesma sala, problemas distintos sejam explorados por diferentes alunos ou grupos de alunos. Dessa maneira, se permite que cada aluno ou dupla de alunos esteja se dedicando a uma questão, ou seja, o tempo de cada aluno é respeitado de acordo com as necessidades dos envolvidos. Um aluno que resolva rapidamente o primeiro problema não precisa, necessariamente, esperar para ir adiante. Embora situação similar possa ocorrer em uma sala de aula com quadro e giz, sem o uso desse recurso ela se torna menos viável. Por exemplo, seria necessário aguardar que todos copiassem o que foi escrito no quadro para poder prosseguir. Além disso, é preciso esperar que muitos concluam para proceder a uma correção coletiva. Usando o ODA, o aluno resolve, salva sua solução e inicia outro problema.

O tema Análise Combinatória foi escolhido por não ser muito explorado nos anos iniciais (Silva, 2016). Piaget descreve que o estágio das operações formais é atingido quando são dominadas as operações combinatórias (Inhelder \& Piaget, 1976). Assim, o ODA pretende ser uma possibilidade de inserção maior desse tema nas salas de aula de ensino regular.

No primeiro encontro com os alunos, algumas duplas resolveram três problemas, enquanto outras não concluíram o primeiro. Independente de quantos problemas resolveram, todos se envolveram com o mesmo tema e com a mesma proposta. Além do fator tempo ser primordial, outras questões levaram à decisão por usar material digital, sendo o limite de produzir material físico, uma delas. Como exemplo dessa dificuldade, pode-se tomar uma das questões do objeto, o problema "Pódio" descrito a seguir. Neste problema é perguntado de quantos modos diferentes pode-se alocar quatro crianças em um pódio. Caso fosse um objeto físico, similar ao ODA atual, a resposta (vinte e quatro) iria requerer dezoito "peças" de cada criança, totalizando setenta e duas peças no total.

A produção de dados a partir do uso do ODA foi realizada em turmas regulares de uma escola pública de Porto Alegre, de maneira que participavam simultaneamente cerca de 20 alunos organizados em duplas. Caso se operasse com objetos físicos, para garantir o ritmo de pesquisa seriam necessárias setecentas e vinte peças e, para não comprometer as próximas duplas a realizarem a atividade, essas peças não poderiam ser perdidas ou estragadas. Como o objeto digital contempla nove diferentes problemas a serem resolvidos, após resolver um deles, o material físico deveria ser guardado e a dupla receberia outro kit. Por outro lado, com o ODA, ao completar uma das atividades, a próxima está a apenas dois cliques de distância.

\section{Critérios utilizados no desenvolvimento}

Decisões técnicas relacionadas com a escolha de linguagens foram tomadas para o desenvolvimento do ODA. Neste caso, optou-se pelas linguagens HTML5 (Hypertext Markup Language), CSS (Cascading Style Sheets) e JavaScript. Durante o levantamento inicial que buscava diferentes ODA com proposta similar ao que está sendo desenvolvido, notou-se que uma grande parcela deles utilizava o Adobe Flash Player como seu motor principal. Entretanto, visando atualizações futuras e também mais praticidade tanto no 
desenvolvimento quanto na utilização, optou-se pelo HTML5 como ferramenta principal. A principal funcionalidade utilizada no ODA é a de arrastar e soltar (Drag\&Drop). Essa funcionalidade é oferecida nativamente pelo HTML5. Outra razão é a compatibilidade com uma variedade maior de dispositivos. O Flash não é suportado em dispositivos móveis da Apple, que em 2017 foi a maior vendedora de tablets do mundo, possuindo mais de 20\% das vendas desse mercado (Huang, Ubrani, Shirer, 2017). Além disso, o HTML5 possibilita fazer tanto quanto o Adobe Flash Player, de modo que vem se tornando um dos standards mais populares da internet, considerando que

HTML5, o novo web standard que foi adotado pela Apple, Google e muitos outros, permite aos desenvolvedores da web criarem gráficos avançados, tipografia, animações e transições sem depender de plugins de terceiros para navegadores (como o Flash). (JOBS, 2010, tradução nossa).

O ODA desenvolvido também foi planejado de maneira que seu código fique disponível para download, possibilitando fazer alterações/adaptações por outros usuários de acordo com sua necessidade ou finalidade de uso. Nessa perspectiva, é necessário que o ODA esteja disponível em uma linguagem que seja consistente e ofereça segurança ao usuário. Isso não seria possível caso ele fosse desenvolvido em Flash, pois a distribuição e atualização do programa serão encerradas a partir de 2020, sendo que a recomendação da própria empresa Adobe é que qualquer conteúdo desenvolvido em Flash seja migrado para outros formatos abertos, como o HTML5 (Adobe, 2017).

Para o desenvolvimento do ODA também foram levados em consideração os aspectos técnicos robustez, portabilidade e interface, destacados por Reategui, Boff e Finco (2010). A robustez trata da funcionalidade do objeto, se é isento de erros e se possui estabilidade durante a utilização. A portabilidade trata da sua utilização em diferentes dispositivos com diferentes configurações, outra forte razão para utilização do HTML5. No quesito interface, se trabalha o bom uso de imagens, texto e demais recursos acerca da utilização, de maneira a torná-lo agradável ao usuário.

\section{Processo de desenvolvimento do ODA}

O ODA apresenta nove diferentes problemas envolvendo Análise Combinatória. Cada problema encontra-se em uma página, onde é apresentado um enunciado, uma pergunta inicial e uma caixa para a inserção da resposta numérica. Abaixo da pergunta, há diferentes imagens (ícones representando elementos mencionados no enunciado da questão) e, sob elas, há outra área, essa agora com espaços vazios. A proposta principal do ODA é que as diferentes imagens dispostas sejam "arrastadas" para os espaços vazios, para que sejam construídas as possibilidades previstas no problema e encontrar, através da contagem, a resposta numérica à pergunta.

O primeiro problema desenvolvido foi o "Uniforme da Colômbia". Por ser o primeiro, este apresenta todas as modificações que foram feitas durante o processo. Uma vez que os problemas funcionam de maneira semelhante, algumas funcionalidades modificadas nesta versão foram implementadas já na primeira versão dos demais problemas. Neste caso, o problema combinatório consiste em montar o maior número de uniformes diferentes, conforme o enunciado: 
"A bandeira da Colômbia é azul, vermelha e amarela com um brasão. Para os uniformes do time de vôlei a equipe do vestuário tem a disposição camisetas vermelhas, amarelas e azuis. Da mesma forma, os calções disponíveis são lisos, nas cores azul, vermelha ou amarela. Quantos uniformes diferentes (camiseta+calção) podem ser formados com essas opções de camiseta e calção?".

A versão inicial dessa atividade contava com algumas das funcionalidades que seriam mantidas até a versão atual do ODA, sendo a mais importante a possibilidade de poder arrastar e soltar as imagens (Drag\&Drop), que é uma função central em todos os problemas. Essa função foi construída utilizando uma habilidade nativa do HTML5, que permite criar essa funcionalidade de forma simples e responsiva.
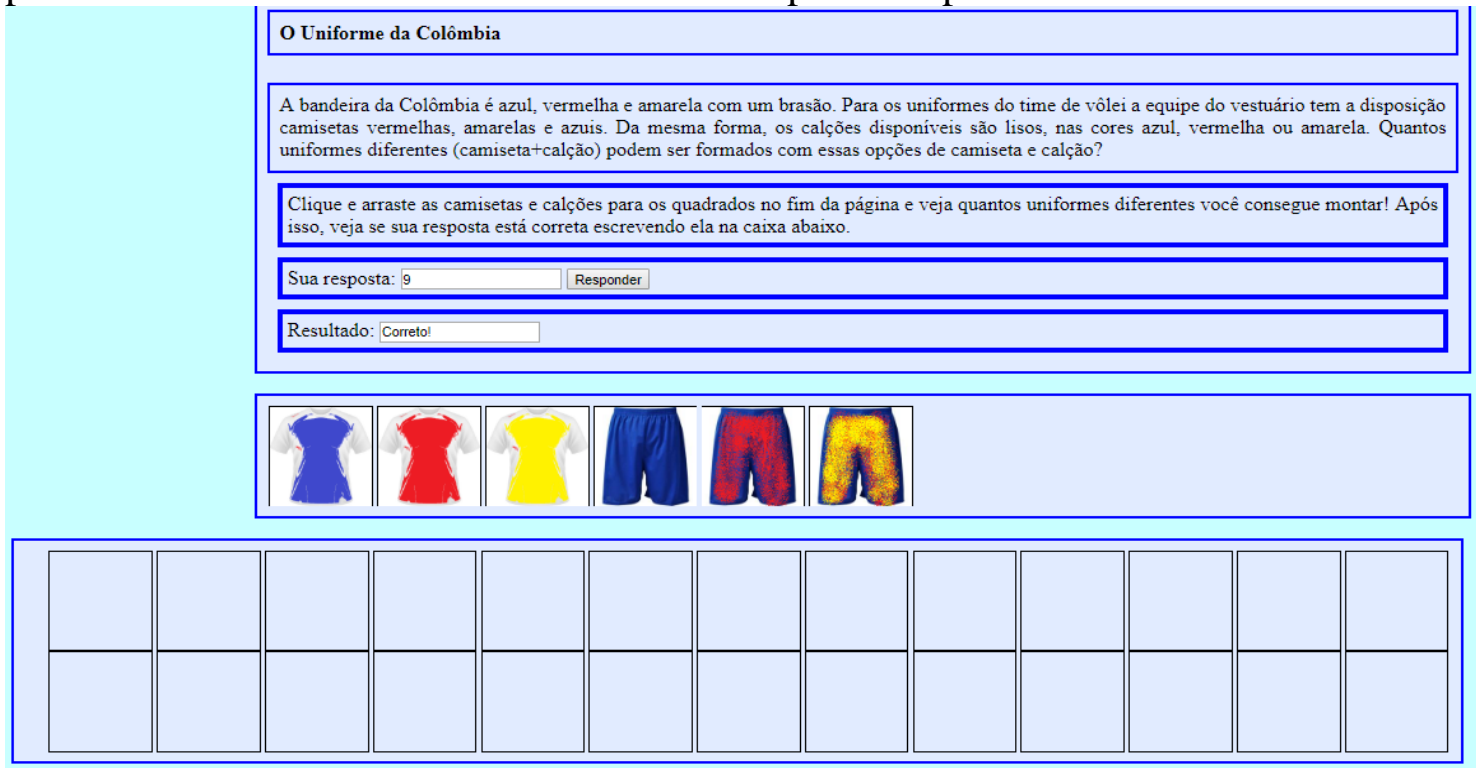

Figura 1: Print primeira versão do problema Uniforme da Colômbia. Fonte: autores.

Observa-se também que a primeira versão (1.0) apresenta uma caixa para a inserção de resposta e uma caixa de resultado. A caixa de resultado foi o primeiro meio pensado para dar um feedback instantâneo para o usuário neste objeto digital. Já na segunda versão (1.1) essa caixa foi removida e substituída por um alerta no topo da página que informa se a resposta está certa ou errada. Outra adição é um ícone de megafone que permite ouvir a leitura da questão, possibilitando aos alunos com pouca fluência de leitura uma compreensão da questão proposta.

A versão 1.2 trouxe uma atualização importante, pois o ODA pararia de informar simplesmente se a resposta está correta ou incorreta. Caso a questão esteja incorreta, ele dá um informativo baseado no erro cometido, se o valor é menor que a resposta ele retorna "Tem certeza que verificou todas as possibilidades?"; caso o valor seja maior, a mensagem informada é "Não cometeu nenhum erro durante a contagem?". Essa alteração é importante por trazer uma orientação e propor uma reflexão sobre a construção das possibilidades e foi implementada com o intuito de auxiliar a superar a dificuldade que leva ao erro. Ler a mensagem de que a resposta está incorreta não auxilia na busca pela solução, mas uma pergunta ou uma dica podem trazer à tona questões que não haviam sido pensadas durante a realização da atividade. 
A versão 1.3 trouxe duas atualizações: 1) Possibilidade de interromper a leitura da pergunta e retomá-la do princípio. Após a leitura ter sido iniciada, caso o usuário clique no ícone novamente a leitura irá parar, ao clicar mais uma vez, a leitura será reiniciada. 2) Inclusão de perguntas adicionais após a primeira ter sido corretamente respondida. No caso do problema dos uniformes, ao acertar a resposta, as perguntas "Em quantas dessas opções o uniforme fica de uma cor só?", "Em quantas dessas opções o uniforme tem alguma peça azul?" e "Em quantas dessas opções o uniforme não possui nenhuma peça amarela?" irão aparecer embaixo da pergunta inicial. Elas funcionam da mesma forma que a pergunta original, após ser inserida a resposta e clicar em "Responder" aparecerá um alerta informando se o valor informado é correto ou não. Cabe ressaltar que as construções feitas não desaparecem e podem ser ampliadas ou reorganizadas para que as questões adicionais sejam respondidas.

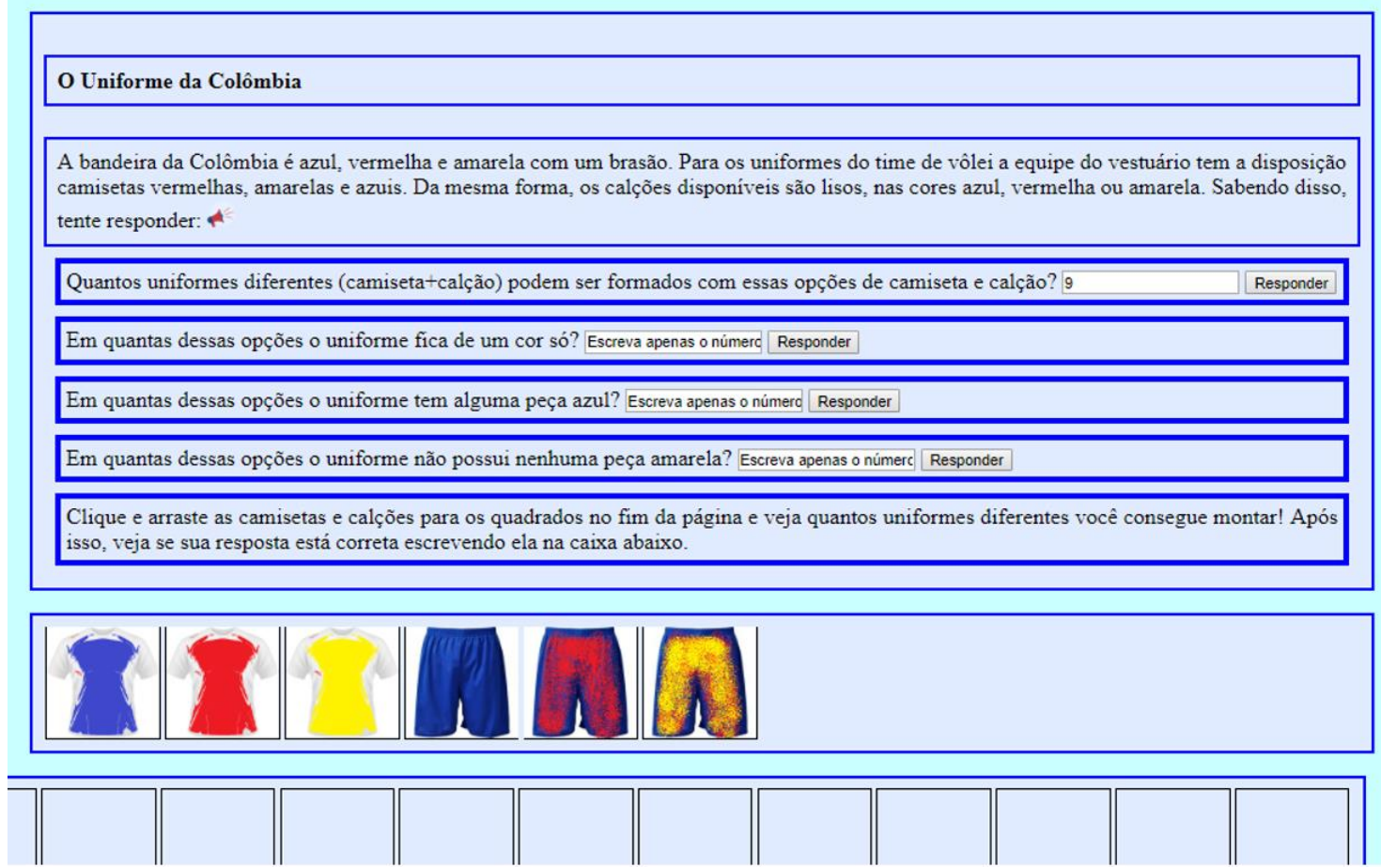

Figura 2: Print da versão 1.3, com as questões adicionais. Fonte: autores.

$\mathrm{Na}$ versão 1.4 houve a substituição das imagens utilizadas. Como o foco era garantir as funcionalidades básicas do ODA, até aqui haviam sido usadas imagens coletadas no Google Imagens, que não seriam publicizadas. A partir da versão 1.4 foram usadas imagens criadas especificamente para o ODA ou retiradas de material digital com licença que permitisse tal uso.

A versão 1.5 trouxe as implementações mais importantes no quesito funcionalidade: botões que permitem apagar alguma construção criada e a opção "Mostrar mais", que permite que sejam criados mais espaços para a criação de uniformes. Até esse momento não havia a possibilidade de desfazer algum erro cometido durante a montagem da resposta. Caso algum engano fosse cometido, era necessário recarregar a página e reiniciar todo o processo de construção do princípio. Uma das alternativas testadas foi a de ao arrastar uma imagem por cima de alguma outra posicionada anteriormente, a imagem mais antiga seria apagada, operando quase como uma "borracha". Entretanto, 
essa alternativa foi descartada por não ser consistente o suficiente e por apenas permitir trocar as imagens e não remover por completo alguma opção criada. Os botões atuais para apagar funcionam consistentemente, permitindo construir e refazer as possibilidades necessárias para responder às questões propostas conforme necessário. O botão "Mostrar mais" foi colocado para possibilitar aumentar a sua área de trabalho conforme necessário, deixando a tela menos poluída visualmente e retirando o limite de possibilidades imposto pelo ODA.

As alterações presentes na versão 1.6 foram mais focadas no design e em alguns ajustes de funcionalidade. O botão "Mostrar mais" foi atualizado de modo a ser mais chamativo e harmônico com o restante do visual do ODA. O ícone megafone foi adicionado aos outros textos e perguntas. A última modificação nessa versão é a limitação sobre o tipo de imagem que pode ser colocado em cada espaço. No problema dos uniformes, por exemplo, cada uniforme montado deve ser formado por duas peças de roupa; e, a partir dessa versão, as camisetas só podem ser colocadas no espaço superior e os calções nos espaços inferiores. Ou seja, não seria mais possível montar um uniforme com duas camisetas ou dois calções como nas versões anteriores.

A atual versão (1.7) trouxe poucas diferenças da anterior, mas que não deixam de ser importantes para o objetivo educacional do ODA. O texto com as instruções, que estava disposto junto da pergunta, foi substituído por um botão. Ao clicar sobre ele, surge uma janela com o texto que explica como utilizar as ferramentas. Outra modificação que traz mais conforto ao uso é a possibilidade de apertar a tecla "enter" para enviar a resposta, não sendo obrigatório clicar no botão "responder".
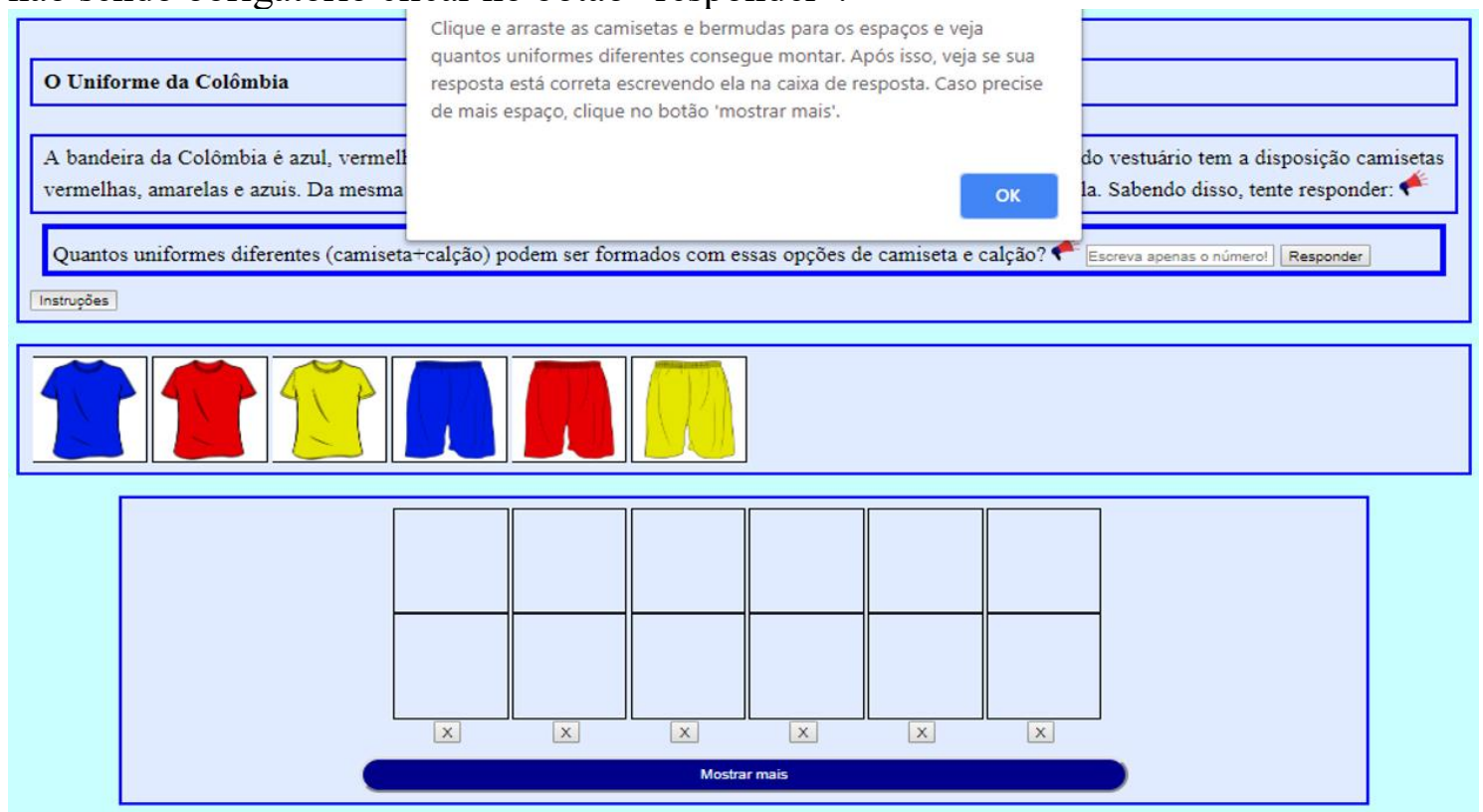

Figura 3: Print da versão 1.7 com a caixa de instruções visível. Fonte: autores.

Entre a versão 1.4 e 1.5 houve o início do desenvolvimento do problema seguinte: o "Pódio". A partir desse momento, as duas atividades passaram a evoluir de maneira concomitante, pois conforme alguma modificação era implementada em um, o outro em seguida já recebia a mesma implementação.

Quando os nove problemas estavam em fase final de programação, percebeu-se a necessidade de agrupar todos em um mesmo lugar. Foi desenvolvida uma página webcom 
uma tela inicial que permite acessar cada um dos problemas a partir de uma imagem. Esta tela inicial conta com uma barra de menu na parte superior da tela (que também está presente em todos os diferentes problemas), permitindo uma navegação mais confortável entre as páginas e também para providenciar em um local central informações prioritárias, como as instruções de utilização do ODA.

As últimas atualizações realizadas no ODA foram feitas baseadas em alguns resultados observados na sua utilização. A possibilidade de aumentar a área de trabalho foi alterada para que seja possível adicionar espaço tanto horizontalmente quanto verticalmente, dependendo da vontade do usuário. Houve também a adequação de algumas das mensagens exibidas quando uma resposta incorreta é inserida. Por exemplo, no problema "Loja de Brinquedos", um erro comum é inserir a resposta 12, sendo que a resposta correta é 6 . Devido a isso, quando a resposta 12 é inserida, a mensagem "Escolher elefante e zebra é o mesmo que escolher zebra e elefante? Na hora de levar para casa, em uma sacola, essas duas opções são iguais ou diferentes? Reveja as possibilidades construídas" é exibida, pois ela trata do erro cometido de maneira específica. Além disso, algumas perguntas adicionais foram adicionadas aos problemas.

\section{Resultados preliminares}

O ODA foi utilizado por alunos do quarto ano do ensino fundamental de uma escola pública de Porto Alegre como parte da produção de dados de uma pesquisa de doutoramento. Entretanto, o mesmo uso serviu como fase de validação do ODA desenvolvido. Os encontros nos quais o ODA foi utilizado foram gravados em vídeo e as soluções finais de cada problema foram salvas utilizando-se de capturas de tela para que pudessem ser analisadas posteriormente. A partir dos registros feitos em vídeo foram propostas alterações relevantes para a versão final do ODA.

Os alunos envolvidos com o ODA não haviam abordado problemas de combinatória em aula. Salienta-se também que não foram apresentados conceitos ou teorias sobre a temática posteriormente ao uso do ODA. Ao resolverem um problema, era feita uma captura de tela com a solução construída. Essas imagens foram analisadas e permitiram conclusões interessantes. Alguns dos resultados que podem ser observados a partir de uma primeira análise das respostas salvas pelos alunos é que, embora o número de soluções corretas e completas não seja muito expressivo, em especial em alguns dos problemas mais complexos, fica perceptível a presença de evidências de uso de sistematização na construção da resposta.

O gráfico representado na figura 4 , indica que os primeiros problemas foram resolvidos corretamente pela maioria dos envolvidos. Os problemas 5, 7 e 9, com menor percentual de acertos, envolviam respostas maiores. Ou seja, era necessário gerar 36, 24 e 24 casos, respectivamente, para se obter a resposta correta. O problema 8 tem como resposta 21 e, apesar de envolver um grande número de possibilidades, teve mais de $60 \%$ de respostas corretamente geradas. Os percentuais de utilização de esquemas de sistematização evidenciam que nos problemas 5, 7 e 8 o uso de sistematização foram mais expressivos. Isso se deve à dificuldade de conferir os casos já construídos sem que haja uma organização dos casos representados. Essa organização é obtida pela sistematização da construção das soluções. Esse fato é relevante para a pesquisa porque a sistematização não é natural para alunos da faixa etária envolvida (Inhelder \& Piaget, 1976). 


\section{Construção de todos os casos possíveis por problema (5)}

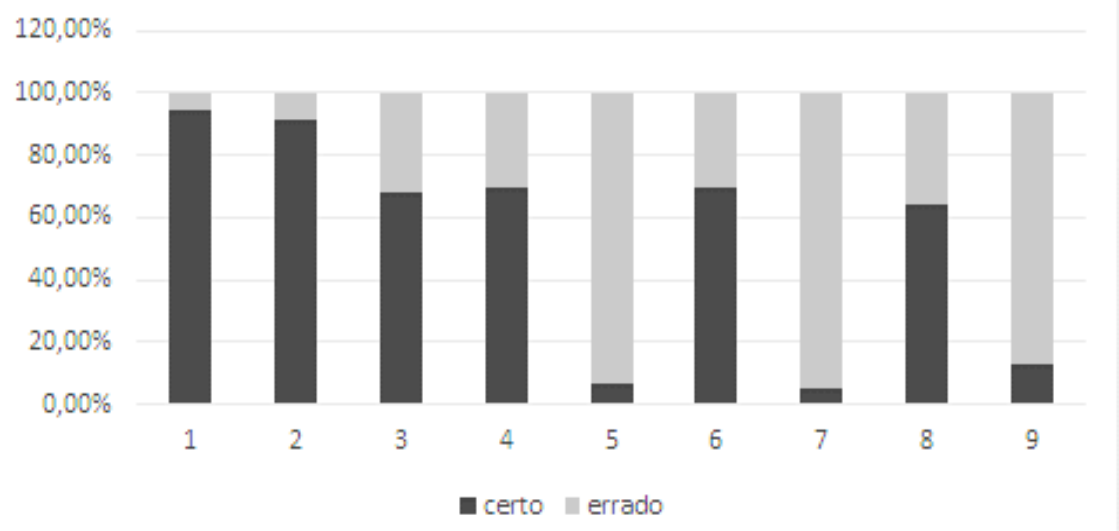

Figura 4: Gráfico com o percentual de acertos por problema. Fonte: Martins, E. F. (2018).

Evidências de sistematização na realização dos problemas (\%)

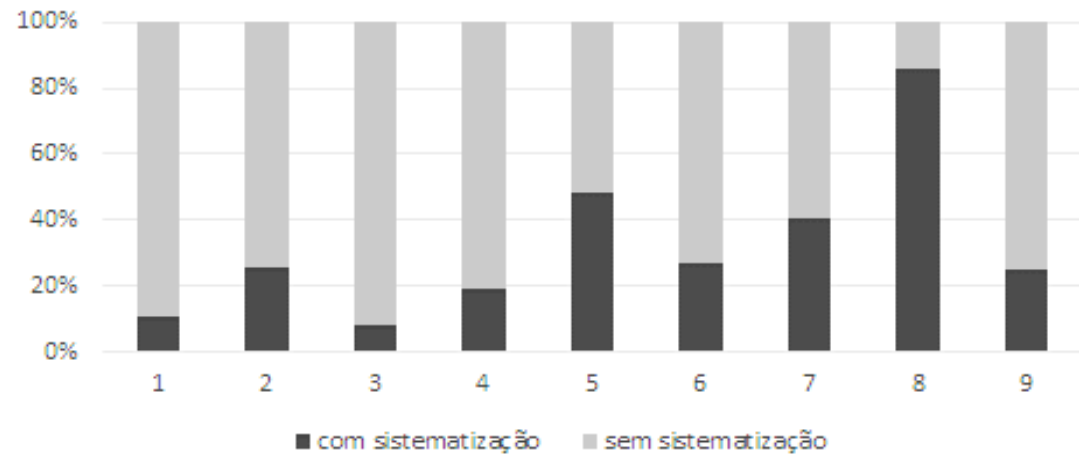

Figura 5: Gráfico com os percentuais de evidência de sistematização na construção das soluções. Fonte: Martins, E. F. (2018)

Também deve ser destacado que, conforme o número de possibilidades para uma determinada resposta assume um valor mais alto (maior que 10 por exemplo), a sistematização acaba se tornando mais frequente em termos de estratégia evidenciada nas respostas.

O problema "Notas", referido com o número 8 nos gráficos acima, possui o seguinte enunciado:

"Considerando que nosso sistema monetário possui 6 cédulas diferentes (de 2, 5, 10, 20, 50 e 100 reais): Quantos valores diferentes posso ter se eu tenho duas cédulas em minha carteira?

De quantas formas posso ter mais do que 21 reais?

Em quantos desses valores eu tenho duas notas iguais?

Em quantos desses valores eu tenho duas notas diferentes?".

Mesmo sendo uma questão relativamente complexa, 64,3\% das soluções analisadas estavam corretas e completas. Além disso, mesmo que a resposta não estivesse 
completa, de todas as construções analisadas, $85,7 \%$ evidenciava o emprego de algum tipo de sistematização.

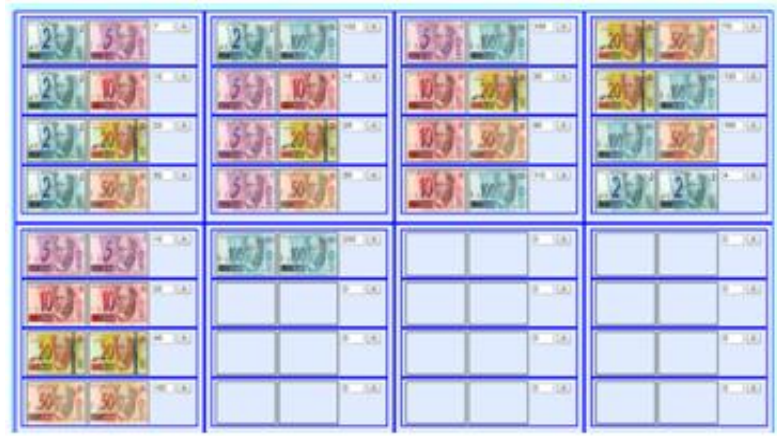

Figura 6: Solução para o problema das notas Fonte: participantes da pesquisa.

Analisando as respostas de um problema de menor complexidade, vê-se que não há de maneira tão presente o uso da sistematização, pois é mais simples de verificar se há repetições se o número de construções possíveis for menor. O problema "Caras Malucas", referido com o número um nos gráficos anteriormente apresentados, lê-se:

"Um designer resolveu criar emoticons novos para um aplicativo de comunicação. Ele inventou 3 tipos diferentes de olhos e desenhou 3 bocas. Quantos emoticons podem ser formados combinando essas bocas com esses olhos?

Quantos emoticons estão de língua de fora?

Quantos emoticons estão de olhos abertos?"

Para esse problema, entre as respostas analisadas como corretas, apenas 10,8\% apresentam algum tipo de sistematização. Mesmo assim, 94,6\% de todas as respostas estavam corretas.
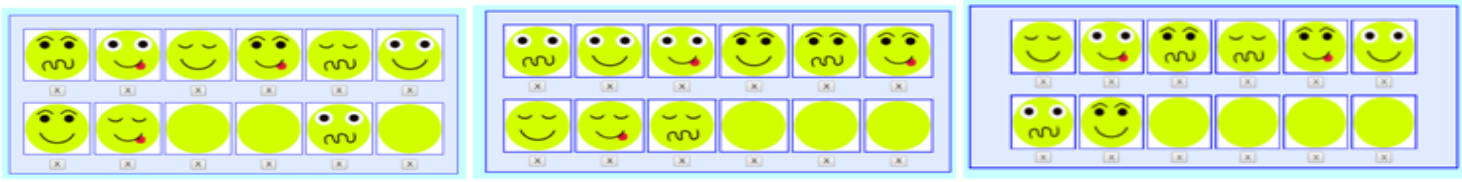

Figura 7: Soluções para o problema Caras Malucas. Fonte: participantes da pesquisa.

A dificuldade de trabalhar com um número grande de possibilidades acaba por exigir que os estudantes elaborem uma maneira de organizar a contagem, pois a simples verificação visual pode não ser suficiente para garantir a não repetição das construções.

\section{Considerações finais}

O desenvolvimento de um ODA requer um conjunto de especificidades para garantir que o seu uso por estudantes e professores permita atingir os objetivos de aprendizagem estabelecidos. Tanto a atenção aos requisitos técnicos quanto os objetivos pedagógicos para o desenvolvimento de objetos têm o potencial para estabelecer aproximações entre a formação de professores e a criação e desenvolvimento desse tipo de objeto. Aspectos teóricos como os princípios do Método Clínico Piagetiano e mesmo a ideia central de que para aprender é preciso ação, também de cunho piagetiano, foram fundamentais para o desenvolvimento do ODA. Suas funcionalidades, a maneira de apresentar o problema e as perguntas não foram decididas apenas a partir de questões técnicas. Buscou-se atender aos quesitos técnicos alinhados aos aspectos teórico- 
pedagógicos que contribuíssem no processo de aprendizagem presentes na resolução dos problemas. Na construção do ODA, a ação do usuário e a antecipação de possíveis dificuldades no uso, foram fundamentais para o desenvolvimento do objeto.

Considerando a realidade da educação atual, uma atualização futura planejada é o suporte para telas de toque, tal como tablets e alguns computadores. Como o ODA não tem seu uso indicado para telas muito pequenas por necessitar de um bom espaço visual, smartphones não estão sendo considerados como prioridades. Porém, muitos desses aparelhos apresentam sistemas operacionais e recursos semelhantes a tablets, então também terão alguma espécie de suporte.

A sala de aula do futuro necessitará de novos materiais e meios de interagir com o aluno. Considera-se que para isso será fundamental que professores saibam utilizar recursos das tecnologias digitais atualmente disponíveis e que também possam criar e desenvolver novos recursos conforme a sua necessidade, para que possam se manter evoluindo profissionalmente juntamente na sua ação com estudantes dos diferentes níveis de ensino.

\section{Referências}

ADOBE CORPORATE COMMUNICATIONS. Flash \& The Future of Interactive Content. 2017. Disponível em: https://theblog.adobe.com/adobe-flash-update/. Acessado em 20 de outubro de 2018.

BASSO, M. V. A.; MARTINS E. F. Concepção de Objetos Digitais de Aprendizagem para Combinatória nos Anos Iniciais. In: Revista Novas Tecnologias na Educação. V. $16 \mathrm{~N}^{\mathrm{o}} 1,2018$.

HUANG, L.; UBRANI, J.; SHIRER, M. Tablet Market Declines 5.4\% in Third Quarter Despite 4 of Top 5 Vendors Showing Positive Year-Over-Year Growth, According to IDC.2017. Disponível em: https://www.idc.com/getdoc.jsp?containerId=prUS43193717. Acessado em 20 de Outubro de 2018.

INHELDER, B.; PIAGET, J. Da lógica da criança à lógica do adolescente:Ensaio e construção das estruturas operatórias formais. São Paulo: Livraria Pioneira Editora, 1976.

JOBS, S. Thoughts on Flash. 2010. Disponível em: https://www.apple.com/hotnews/thoughts-on-flash/. Acessado em 20 de Outubro de 2018.

MARTINS, E. F. Uma aula de combinatória na escola primária: usando Objeto Digital de Aprendizagem. In: RODRIGUES, A., BARBOSA, A., SANTIAGO, A., DOMINGOS, A., CARVALHO, C., VENTURA, C., ... CARREIRA, S. (Eds) Livro de Atas do EIEM 2018, Encontro em Investigação em Educação Matemática, pp. 127-146, Coimbra, Portugal, 2018.

REATEGUI, E.; BOFF, E.; FINCO, M. D. Proposta de Diretrizes para Avaliação de Objetos de Aprendizagem Considerando Aspectos Pedagógicos e Técnicos. In: Revista Novas Tecnologias na Educação V. 8 Nº 3, dezembro, 2010.

SILVA, M. C. A combinatória: abordagem em documentos oficiais, em resultados de pesquisas e em livros didáticos do Ensino Fundamental. Dissertação de mestrado, Universidade Federal de Pernambuco, 2016. 